\title{
Analytical method validation for related substances in sodium valproate oral solution by gas chromatography
}

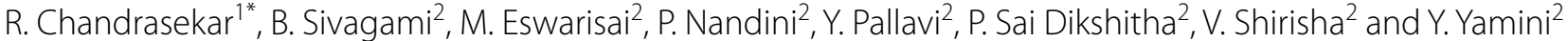

\begin{abstract}
Background: Sodium Valproate is the sodium salt of valproic acid (VPA). Valproic acid is mainly used for the treatment of epilepsy. The specific aim of the study is to develop and validate an optimized method for the determination of six related substances such as $N, N$-dimethyl valpronamide, valeric acid, 2-methyl valeric acid, 2-ethyl valeric acid, 2-isopropyl valeric acid and 2-n-butyl valeric acid in Sodium Valproate Oral Solution by Gas Chromatography. Chromatographic separations of these six related substances were achieved on DB-FFAP fused silica capillary column (30 $\mathrm{m} \times 0.53 \mathrm{~mm}$ ) bonded with a 0.5- $\mathrm{mm}$ layer of macrogol 20,000 2-nitroterephthalate materials used as stationary phase. The six related impurities were extracted using heptane and monitored by Gas Chromatography coupled with flame ionization detector. The performance of the developed method was assessed by evaluating system suitability, method precision, specificity, linearity and range, ruggedness, accuracy, robustness.

Results: The correlation coefficient was within the acceptance criteria in the range of 0.9998 . The evaluated concentrations for Sodium Valproate were in the ranges of $5.05-25.27 \mathrm{ppm}$. The average recovery values were in the range of 92.4-100.4\%. Solution Stability experiments were performed to evaluate the degradation behavior of SVS.

Conclusion: A novel, precise and sensitive GC method was developed, validated and optimized for the determination of six related substances in sodium Valproate oral solution. The results obtained from the validation experiments demonstrated that the method is accurate, precise, linear, specific, sensitive and robust. Hence, the proposed method can be an alternative method, for the determination of related substances in sodium valproate oral solution drug substance.
\end{abstract}

Keywords: Sodium valproate solution, Related substances, Gas chromatography, Flame ionization detector, Validation

\section{Background}

Sodium Valproate Oral Solution is chemically known as 2-propylpentanoic acid. The molecular formula of SVS is $\mathrm{C}_{8} \mathrm{H}_{16} \mathrm{O}_{2}$ and the molecular weight is $144.211 \mathrm{~g} /$ mol. Sodium Valproate is the sodium salt of valproic acid (VPA). Valproic acid is mainly used for the treatment of epilepsy. SVS is an anticonvulsant drug which is used in

\footnotetext{
*Correspondence: chandrumnrcop@gmail.com

${ }^{1}$ Department of Pharmacognosy, Seven Hills College of Pharmacy, Venkatramapuram, Tirupati, Chittoor 517561, Andhra Pradesh, India Full list of author information is available at the end of the article
}

the treatment of seizure disorders, such as tonic-clonic seizures and simple/complex partial seizures [1] and used in mental disorders such as mood changes, bipolar disorder and also effective against migraine headaches [2]. It is used for aggressive behavior in adults and disability [3], patients with mood changes [4] bipolar disorder [5]. The main action of the drug is gamma-amino butyric acid GABA enhancer and also used for treating alcohol withdrawal [6]. The main action is restoring the balance of certain neurotransmitters in the brain. The related substances present in SVS are $\mathrm{N}, \mathrm{N}$-dimethyl valpronamide (DMVA), valeric acid (VA), 2-methyl valeric acid (MVA), 
2-ethyl valeric acid (EVA), 2-isopropyl valeric acid (IPVA) and 2-n-butyl valeric acid (BVA) [7]. These impurities present may originate through the manufacturing process of SVS and the acceptance criteria are based on pharmaceutical studies or known safety data [8]. The overdose and high toxicity levels of SV may lead to death in some cases. Appropriate methods can be used to monitor and control the impurity levels in sodium valproate.

The detector used in FID has few advantages which include the ease of operation, reliability, simplicity and versatility. FID detector will not detect signal for common carrier gases such as $\mathrm{He}, \mathrm{Ar}$, or $\mathrm{N}_{2}$ or contaminants in such gases such as $\mathrm{O}_{2}$ and $\mathrm{H}_{2} \mathrm{O}$. [9] FID connected with temperature programming device is easy to handle and is a best detector used for the routine analysis of organic compounds [10]. The main disadvantage of FID is its destructive nature, so it cannot be connected directly to other GC detectors. FID can be combined and used with other detectors if the carrier gas is split between the FID and the other detector [11].

The literature search reveals that very few analytical methods were reported for the quantification of impurities and the assay of Sodium Valproate. [12]. A specific GC method was developed and validated for the determination of seven related substances in divalproex sodium (DPS) drug substance [13]. A dispersive liquid-liquid micro-extraction coupled with gas chromatography (GC)-flame ionization detector was developed for the determination of valproic acid (VPA) in human plasma. [14] A simple and high throughput method was developed and validated for simultaneous determination of valproic acid and its two toxicant ene-metabolites, 2-enevalproic acid and 4-enevalproic acid in epilepsy patient plasma using liquid chromatography-tandem mass spectrometry [15]. A specific GC-MS method was developed optimized and validated for the determination of five genotoxic impurities, namely Methyl bromide (Me.-Br), Ethyl bromide (Et.-Br), Isopropyl bromide (Ipr.-Br), n-Propyl bromide (n-Pr.-Br) and n-Butyl bromide (n-But.-Br) in Divalproex sodium (DPS) drug substance [16]. Another method was described in a whole blood solid phase extraction of valproic acid, salicylic acid and ibuprofen utilizing butylation for sensitivity and improved chromatography by GC-MS [17]. A rapid, highly efficient, and reliable liquid-liquid microextraction (LLME) methods followed by gas chromatography-flame ionization detection for the extraction, preconcentration, and determination of valproate in human plasma and urine samples were developed [18]. A selective ultra-performance liquid chromatographic (UPLC) method for the quantification of valproic acid and its known related impurities using ion pair reagent has been developed [19]. High-performance liquid chromatography with ultra-violet detection (HPLC-UV) and gas chromatography-mass spectrometry (GC-MS) methods were developed and validated for the determination of chlorambucil (CLB) and valproic acid (VPA) in plasma, as a part of experiments on their anticancer activity in chronic lymphocytic leukemia (CLL). [20] A new high-throughput method was developed for analysis of Valproate in human plasma samples by QuEChERS extraction and gas chromatography-tandem mass spectrometry (GC-MS/MS). [21] Though few analytical methods were developed with GC, GC-MS, HPLC, LCMS, etc., this method indicates the six process-related substances. The main aim of the study was to develop and validate a sensitive and optimized method for the determination of six potential process-related substances in SVS drug substance by GC with FID.

\section{Methods}

\section{Instruments and reagents}

Sodium Valproate Oral Solution was procured from Apollo pharmacy Tirupati. All the other chemicals of analytical grade were procured from standard suppliers. Gas Chromatography Flame Ionization Detector (GC-FID) GC-HS instrument, with column ID DB-FFAP fused silica capillary column $(30 \mathrm{~m} \times 0.53 \mathrm{~mm})$ bonded with a $0.5-\mu \mathrm{m}$ layer of macrogol 20,000 2-nitroterephthalate stationary phase, helium was used as carrier gas, the volume injected was $1.0 \mu \mathrm{l}$, the injector temperature was maintained at $220{ }^{\circ} \mathrm{C}$, the detector temperature was $220{ }^{\circ} \mathrm{C}$, the detector used was Flame Ionization Detector (FID), a split less method was employed, the column flow of Helium was $8.0 \mathrm{ml} / \mathrm{min}$, hydrogen flow was at $35 \mathrm{~mL} / \mathrm{min}$, zero air flow was $350 \mathrm{~mL} / \mathrm{min}$, makeup flow was at $40 \mathrm{~mL} / \mathrm{min}$. Hydrochloric acid $(35 \%, \mathrm{w} / \mathrm{v})$ and HPLC grade heptane were procured from Merck Limited (India). Highly purified water was obtained from Millipore purification system (Merck, India).

\section{Preparation of solutions Preparation of blank}

The blank solution was prepared by taking purified heptane as a blank solution. The Blank Chromatogram is depicted in Fig. 1.

\section{Preparation of sample solution}

The sample solution was prepared by taking a small quantity of the syrup containing $0.50 \mathrm{~g}$ of Sodium Valproate and shaken with $10 \mathrm{~mL}$ of water, acidified with $2 \mathrm{M}$ sulfuric acid and shaken with three $20 \mathrm{~mL}$ quantities of heptane. The combined heptane extracts were washed with $10 \mathrm{~mL}$ of water, shaken with anhydrous sodium sulfate, filtered and diluted to $100 \mathrm{~mL}$ with heptane. Sample Chromatogram is depicted in Fig. 2. 


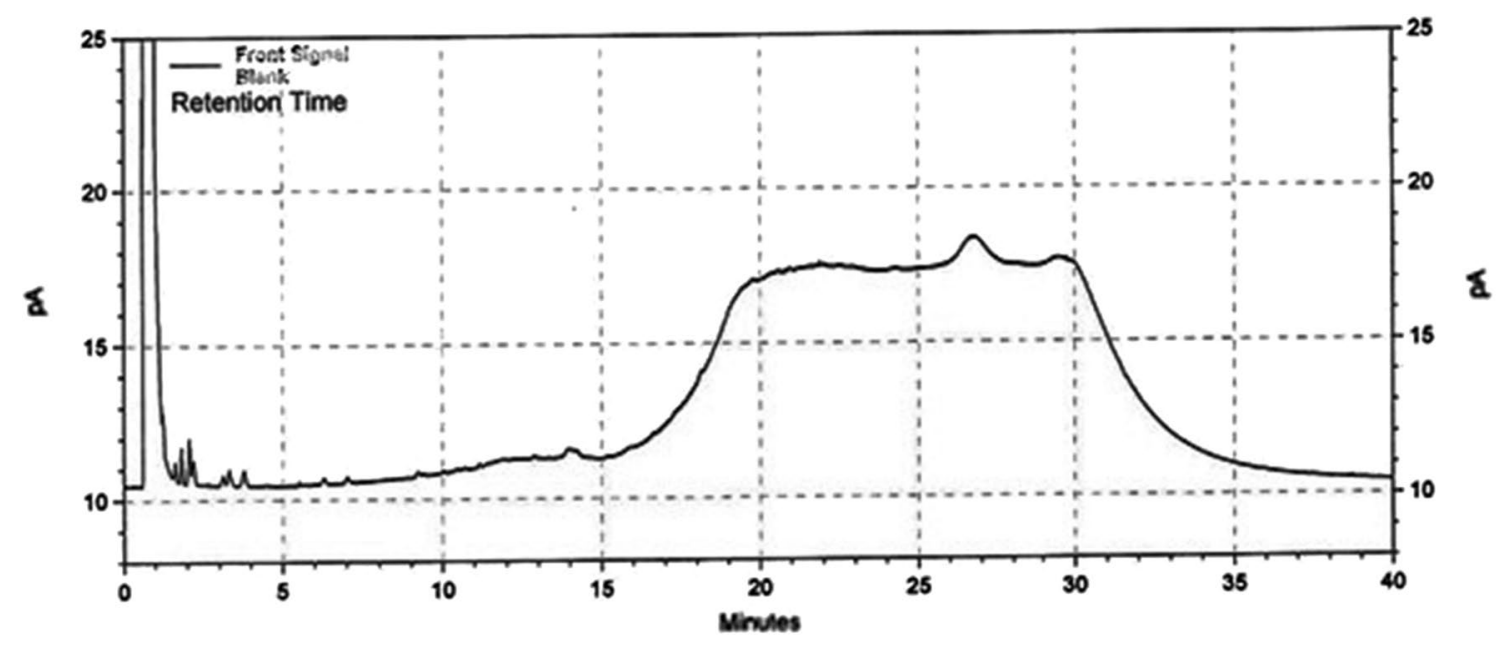

Front Signal Results

Name

RT

Area

Area Percent

Theoretical plates

(USP)

Asymmetry

Fig. 1 Blank chromatogram of sodium valproate

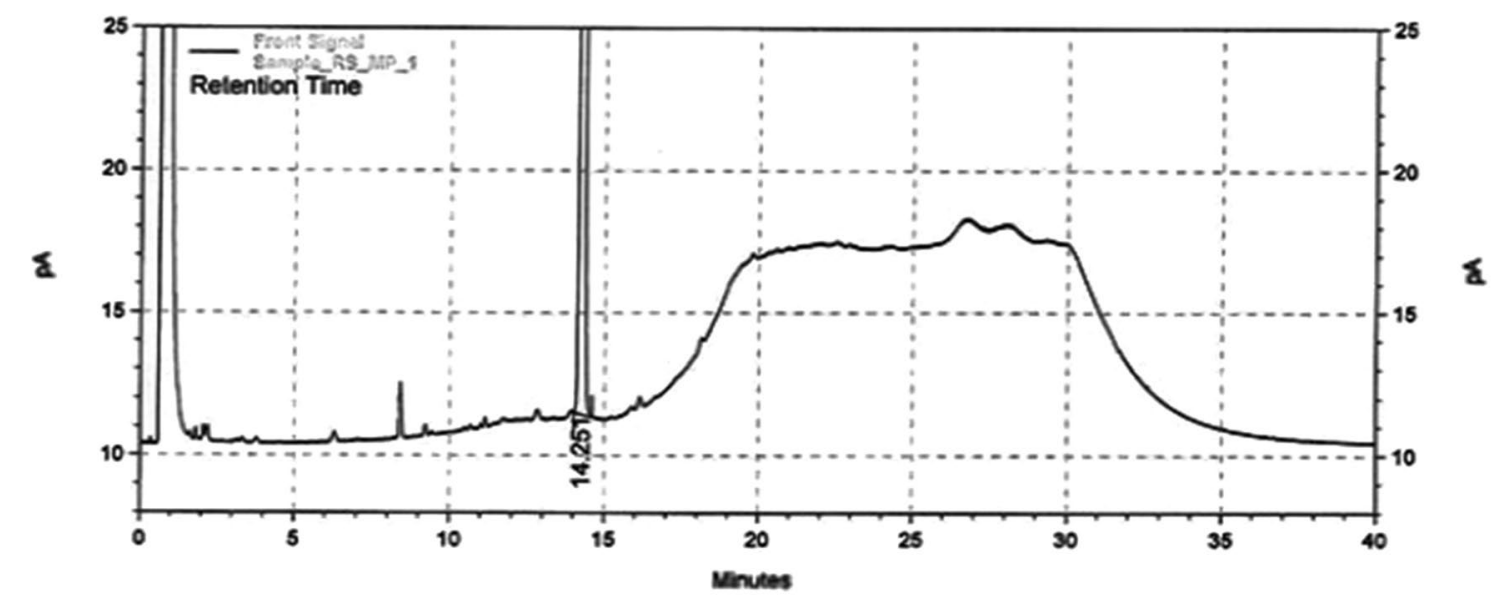

Front Signal Results

\begin{tabular}{|c|c|c|c|}
\multicolumn{1}{c}{ Name } & Area & Area Percent \\
\hline Sodium Valproate & 14.25 & 6149962 & 100.00 \\
\hline Totals & & 6149962 & 100.00 \\
\hline
\end{tabular}

Fig. 2 Sample chromatogram of sodium valproate

\section{Preparation of placebo solution}

The Placebo solution was prepared by shaking $10 \mathrm{~mL}$ of water, acidifying with $2 \mathrm{M}$ sulfuric acid and shaking with three $20 \mathrm{~mL}$ quantities of heptane. The combined heptane extracts were washed with $10 \mathrm{~mL}$ water, shaken with anhydrous sodium sulfate, filtered and diluted to
$100 \mathrm{~mL}$ with heptane. Placebo Chromatogram is depicted in Fig. 3 (Table 1).

\section{Preparation of standard solution}

The standard solution was prepared by diluting 1 volume of solution to 20 volumes with heptane and further 
Table 1 Description of analytical method

\begin{tabular}{|c|c|}
\hline Instrument conditions & Description \\
\hline Column ID & $\begin{array}{l}\text { DB-FFAP fused silica capillary column }(30 \mathrm{~m} \times 0.53 \mathrm{~mm}) \\
\text { bonded with a0.5- } \mu \mathrm{m} \text { layer of macrogol 20,000 2-nitrotere- } \\
\text { phthalate }\end{array}$ \\
\hline Carrier Gas & Helium \\
\hline Injection volume & $1.0 \mu \mathrm{l}$ \\
\hline Injector Temperature & $220^{\circ} \mathrm{C}$ \\
\hline Detector Temperature & $220^{\circ} \mathrm{C}$ \\
\hline Detector & FID \\
\hline Split ratio & Split less \\
\hline Column flow Helium & $8.0 \mathrm{ml} / \mathrm{min}$ \\
\hline Hydrogen Flow & $35 \mathrm{~mL} / \mathrm{min}$ \\
\hline Zero air Flow & $350 \mathrm{~mL} / \mathrm{min}$ \\
\hline Makeup Flow & $40 \mathrm{~mL} / \mathrm{min}$ \\
\hline
\end{tabular}

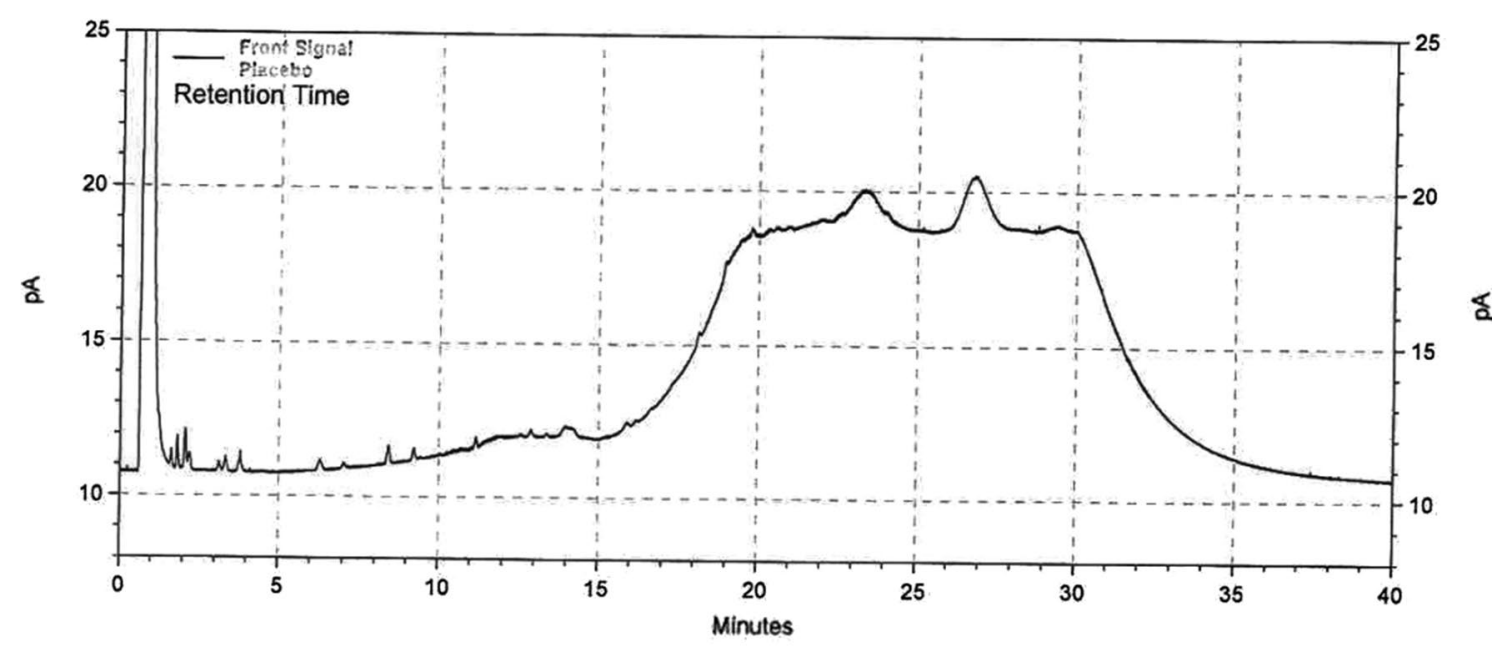

\section{Front Signal Results} Name
RT
Area
Area Percent
Theoretical plates (USP)

Fig. 3 Placebo chromatogram of sodium valproate

diluting 1 volume of the resulting solution to 25 volumes with heptane. Standard Chromatograms RS 1, RS 2, RS 3 , RS 4, RS 5 and RS 6, Chromatograms are depicted in Figs. 4, 5, 6, 7, 8 and 9.

\section{System suitability}

The system suitability parameters were determined by the following method. Standard solutions were prepared as per the test method and injected into GC system. The system suitability parameters such as tailing factor, Theoretical plate and relative standard deviation for peak response of six replicate injections of standard solution were calculated and found to be within the limits. The results are summarized in Tables 2 and 3.

\section{Precision}

The precision of test method was evaluated by analyzing six samples and injected into GC system. The Related Substance in sample was calculated. The relative standard deviations of six preparations in each content were found to be within the acceptance criteria. The results are summarized in Table 3. Figure 4 SRS 1, Fig. 5 SRS 2, Fig. 6 SRS 3, Fig. 7 SRS 4, Fig. 8 SRS 5 and Fig. 9 SRS 6. 


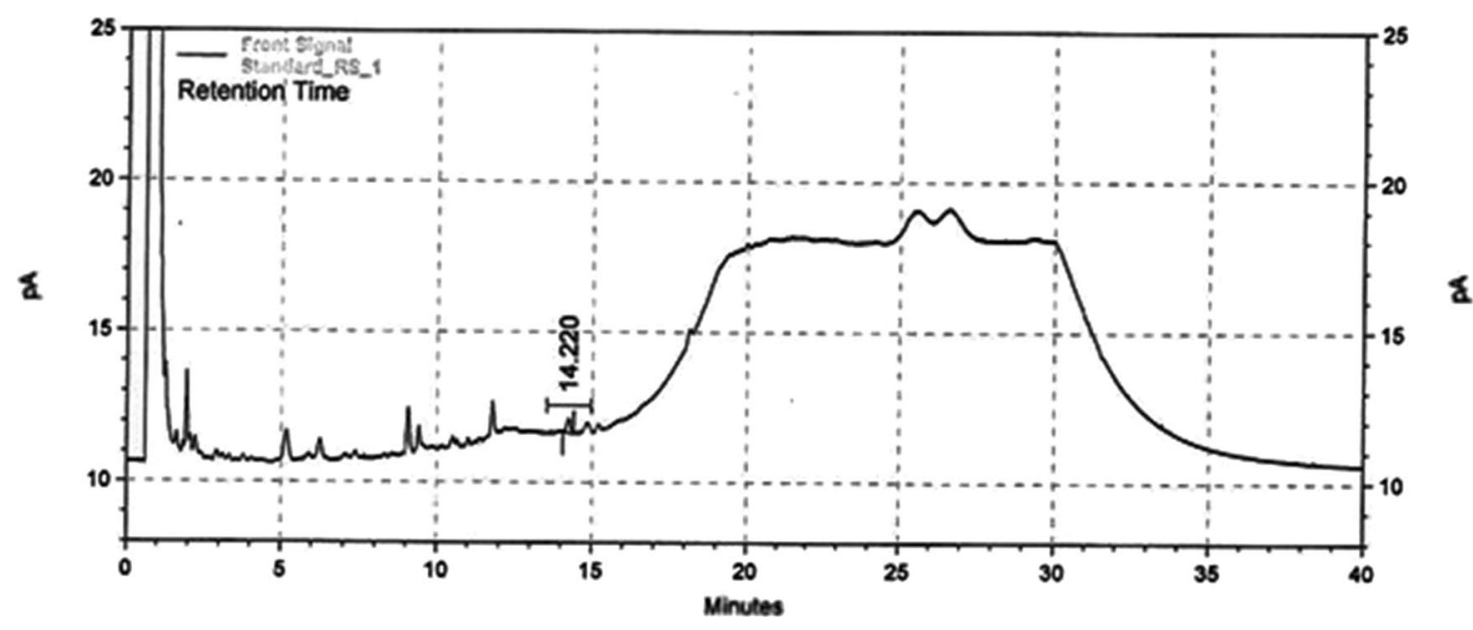

Front Signal Results

\begin{tabular}{|c|c|c|c|c|c|}
\multicolumn{1}{c}{ Name } & RT & Area & Area Percent & $\begin{array}{c}\text { Theoretical plates } \\
\text { (USP) }\end{array}$ & Asymmetry \\
\hline Sodium Valproate & 14.22 & 46336 & 100.00 & 62301 & 1.01 \\
\hline Totals & & 46336 & 100.00 & & \\
\hline
\end{tabular}

Fig. 4 Standard related substance 1 chromatogram of sodium valproate

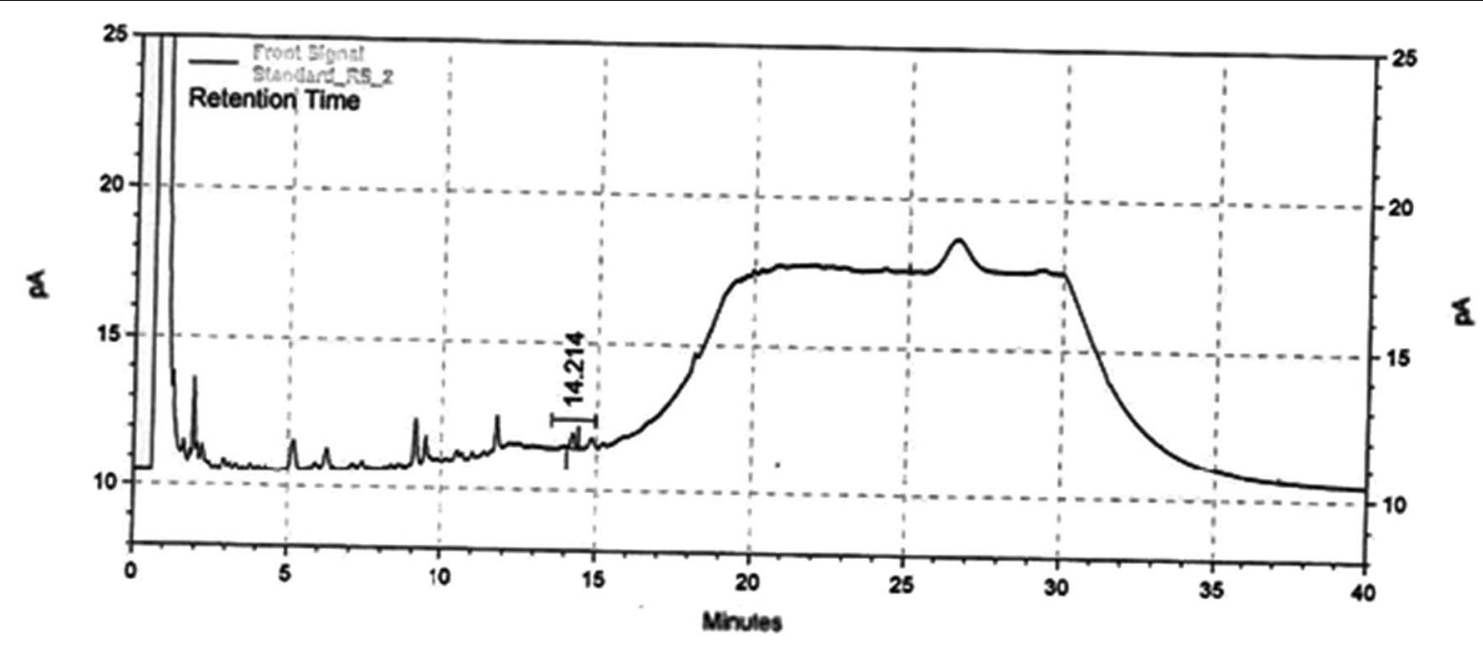

Front Signal Results

\begin{tabular}{|cccc|cc|c|}
$\begin{array}{c}\text { Name } \\
\text { RT }\end{array}$ & Area & Area Percent & $\begin{array}{c}\text { Theoretical plates } \\
\text { (USP) }\end{array}$ & Asymmetry \\
\hline Sodium Valproate & 14.21 & 46743 & 100.00 & 55624 & 1.00 \\
\hline Totals & & 46743 & 100.00 & & \\
\hline
\end{tabular}

Fig. 5 Standard related substance 2 chromatogram of sodium valproate 


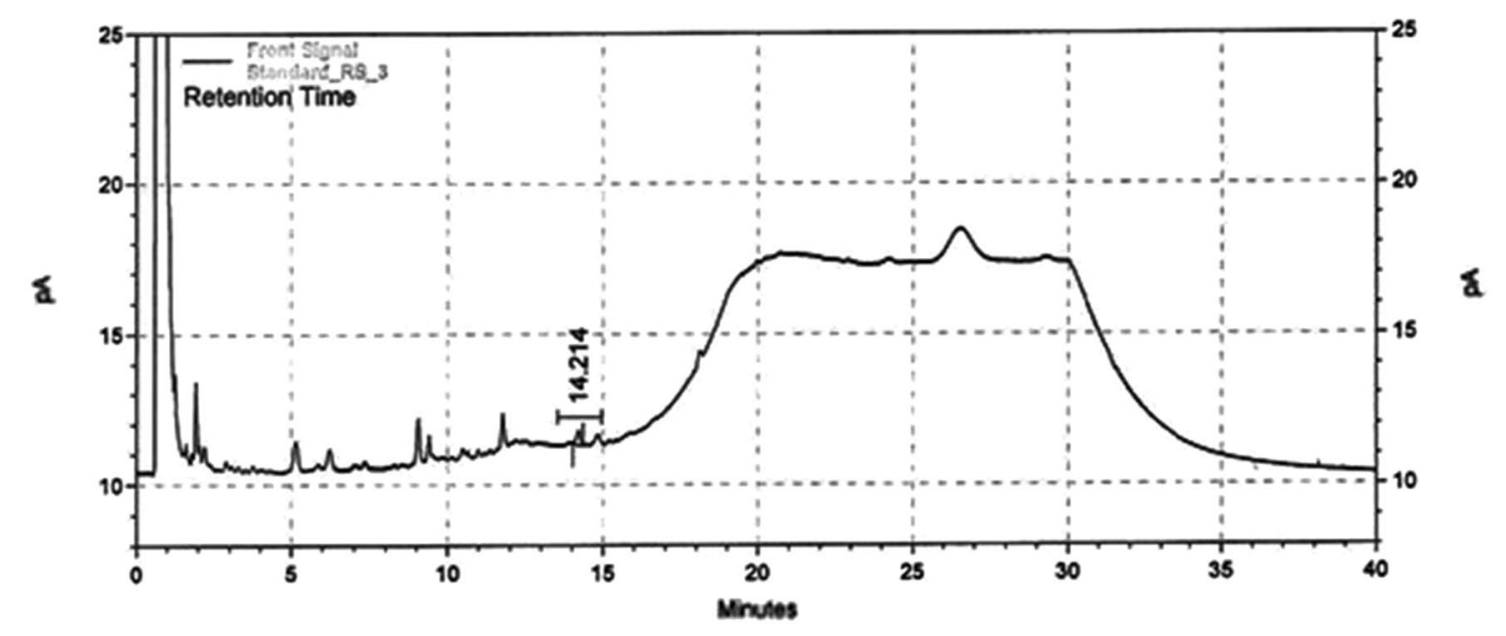

Froat Signal Results

\begin{tabular}{|c|c|c|c|c|c|}
\hline Name & RT & Area & Area Percent & $\begin{array}{c}\text { Theoretical plates } \\
\text { (USP) }\end{array}$ & Asymmetry \\
\hline Sodium Valproate & 14.21 & 46036 & 100.00 & 55649 & 0.97 \\
\hline Totals & & 46036 & 100.00 & & \\
\hline
\end{tabular}

Fig. 6 Standard related substance 3 chromatogram of sodium valproate

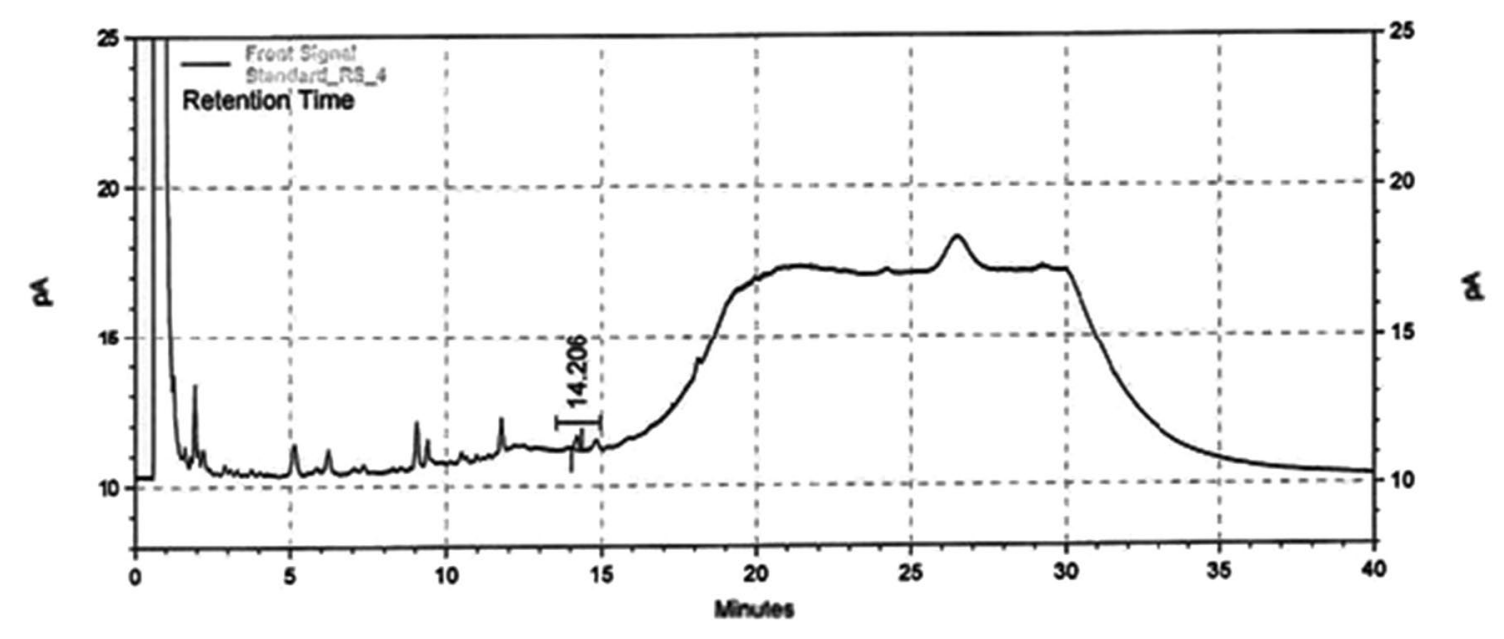

Front Signal Results

\begin{tabular}{|c|cc|c|c|c|}
$\begin{array}{c}\text { Name } \\
\text { Name }\end{array}$ & RT & Area & Area Percent & $\begin{array}{c}\text { Theoretical plates } \\
\text { (USP) }\end{array}$ & Asymmetry \\
\hline Sodium Valproate & 14.21 & 46580 & 100.00 & 55451 & 1.03 \\
\hline Totals & & 46580 & 100.00 & & \\
\hline
\end{tabular}

Fig. 7 Standard related substance 4 chromatogram of sodium valproate 


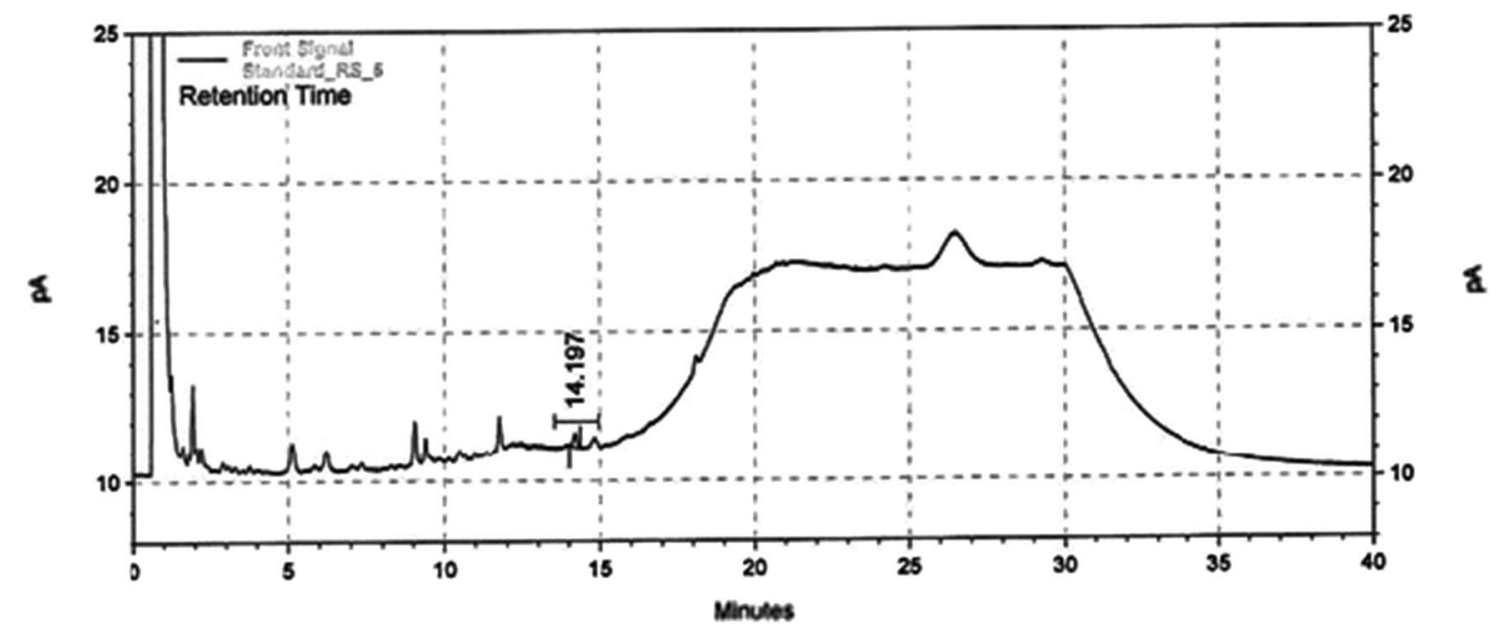

Frort Signal Results

\begin{tabular}{|cccc|c|c|}
$\begin{array}{c}\text { Nrort Signal Results } \\
\text { Name }\end{array}$ & RT & Area & Area Percent & $\begin{array}{c}\text { Theoretical plates } \\
\text { (USP) }\end{array}$ & Asymmetry \\
\hline Sodium Valproate & 14.20 & 46100 & 100.00 & 56103 & 0.98 \\
\hline Totals & & 46100 & 100.00 & & \\
\hline
\end{tabular}

Fig. 8 Standard related substance 5 chromatogram of sodium valproate

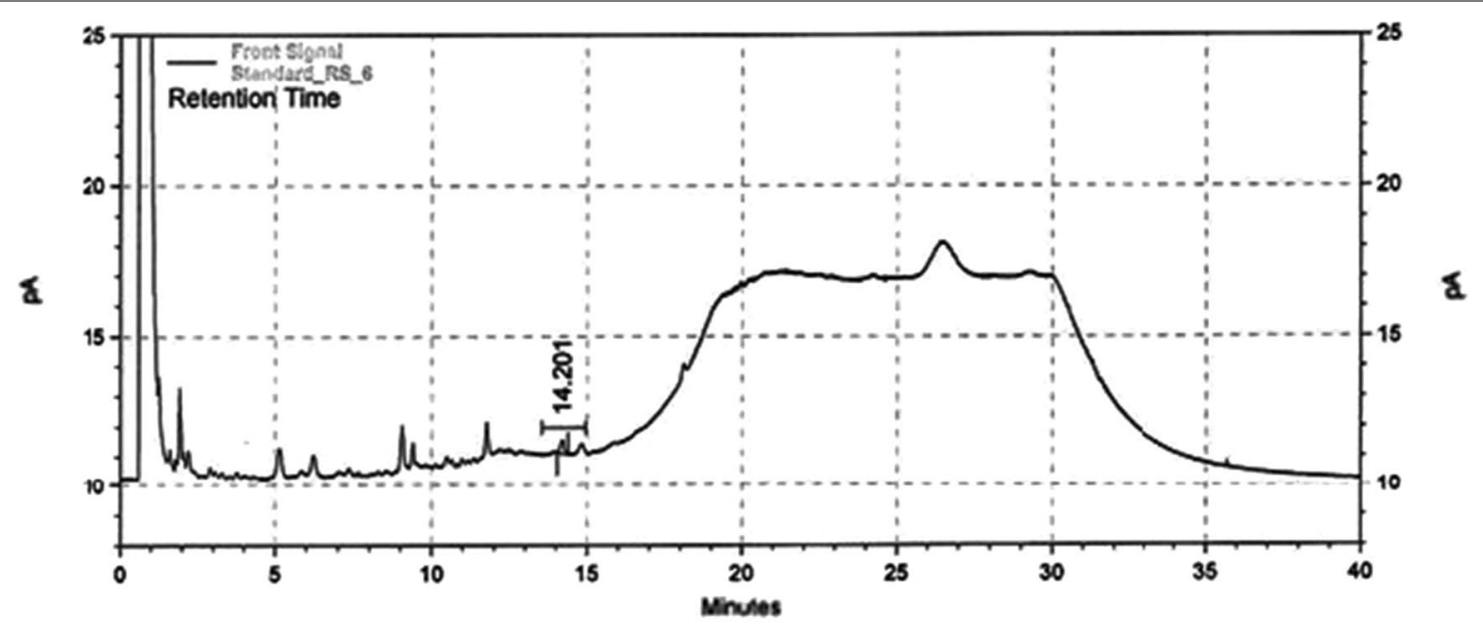

Front Signal Results

\begin{tabular}{c|ccc|c|c|c|}
$\begin{array}{c}\text { Name } \\
\text { Sodium Valproate }\end{array}$ & RT & Area & Area Percent & $\begin{array}{c}\text { Theoretical plates } \\
\text { (USP) }\end{array}$ & Asymmetry \\
\hline Totals & 14.20 & 46744 & 100.00 & 59663 & 1.06 \\
\hline & & 46744 & 100.00 & & \\
\hline
\end{tabular}

Fig. 9 Standard related substance 6 chromatogram of sodium valproate 
Table 2 System suitability parameters

\begin{tabular}{lll}
\hline System suitability parameters & Observed value & Acceptance criteria \\
\hline The \% RSD of six replicate standard injections & 1.3 & NMT 2.0\% \\
$\begin{array}{l}\text { The tailing factor for the Sodium Valproate peak from the first standard injec- } \\
\text { tion }\end{array}$ & 1.3 & NMT 2.0 \\
$\begin{array}{l}\text { The Theoretical plate for the Sodium Valproate peak from the first standard } \\
\text { injection }\end{array}$ & 64,907 & NLT 2000
\end{tabular}

NMT Not more than, NLT not less than

Table 3 Precision results for sodium valproate

\begin{tabular}{ll}
\hline Injection no. & Peak area \\
\hline 01 & 46,474 \\
02 & 47,395 \\
03 & 46,519 \\
04 & 45,581 \\
05 & 46,362 \\
06 & 46,182 \\
Average & 46,419 \\
\% RSD & 1.3
\end{tabular}

Table 4 Specificity for sodium valproate

\begin{tabular}{ll}
\hline Name of the peak & Retention time in minutes \\
\hline Sodium valproate & 14.25 \\
\hline
\end{tabular}

\section{Results}

\section{Specificity}

Specificity was established by taking the blank, placebo, standard solution, test solution and individual standard solutions as per method of analysis and injected into GC system. Chromatograms were evaluated for the interference of blank peaks at the retention time of known peaks in all the solutions. The results are summarized in Table 4

\section{Linearity}

The linearity of test method was determined by preparing the standard solutions from LOQ \% to $250 \%$ of the targeted concentration and analyzed as per the method. The correlation coefficient and Y-intercept were calculated and found to be within the acceptance criteria. The results are summarized in Table 5.

Based on the linearity, precision and accuracy data, the test method was taken from LOQ $\%$ to $250 \%$ of the target concentration. The evaluated concentration for Sodium Valproate is (i.e., $5.05-25.27 \mathrm{ppm}$ ). Linearity of Sodium Valproate is depicted in Fig. 10.
Table 5 Linearity for sodium valproate

\begin{tabular}{lll}
\hline \% Level & Concentration in ppm & Area response \\
\hline LOQ \% & 5.05 & 23,250 \\
$80 \%$ & 7.08 & 37,471 \\
$100 \%$ & 10.11 & 46,714 \\
$150 \%$ & 15.16 & 70,556 \\
$200 \%$ & 20.22 & 95,163 \\
$250 \%$ & 25.27 & 116,419 \\
Correlation coefficient & 0.999 & \\
$y$-intercept & 2141 & \\
\hline
\end{tabular}

\section{Accuracy/recovery}

The accuracy of test method of Sodium Valproate was evaluated from the spiked Placebo. Samples were prepared by spiking Sodium Valproate with Placebo at different levels ranging from LOQ $\%, 100 \%, 150 \%$ and $250 \%$ of the target concentration of known standards. The sample solutions were prepared in triplicate at LOQ $\%, 100 \%$, $150 \%$ and $200 \%$ spike levels and calculated the recovered Sodium Valproate content from the placebo sample. The results are summarized in Table 6.

\section{Robustness \\ Effect of flow variation}

To determine the robustness the flow variation of test method, the blank, placebo, standard and test solutions, were prepared as per the test method and injected with the variation in gas flow (i.e., low and high flow variation), the system suitability parameters were evaluated and calculated for the Related Substance in sample as per the above variant test method.

\section{Solution stability}

The solution stability of test method was evaluated, by taking the standard and test as mentioned in the test method and kept on bench top. Standard and test solutions were injected at initial stages 17th hours and 34th hours. The \% difference of the content of Sodium 


\section{Linearity}

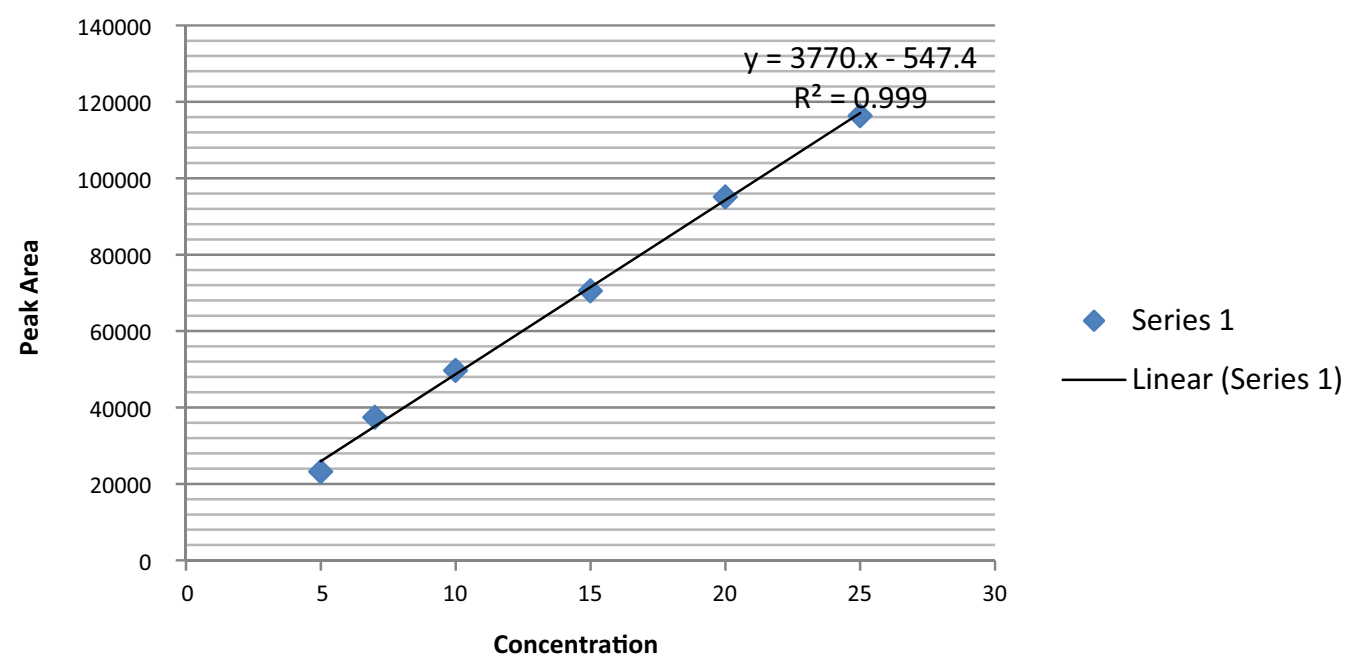

Fig. 10 Linearity of sodium valproate

Valproate solvents in standard and samples were calculated against the initial injection. The results are summarized in Tables 7 and 8.

\section{Discussion}

This work aimed to develop an efficient optimized method for the determination of six process related impurities in Sodium Valproate oral solution. Because of volatility, polar and ionic nature of SVS and its impurities, a GC method with FID by following liquid injection method was chosen. Trial experiments were conducted to select the suitable solvent for extraction using heptane and hence heptane was selected as extraction solvent. In addition, heptane is especially suitable for acidic and basic extraction conditions. $2 \mathrm{M} \mathrm{H}_{2} \mathrm{SO}_{4}$ was used to acidify the SVS sample solution. Finally, for extraction heptane was finalized with $2 \mathrm{M} \mathrm{H}_{2} \mathrm{SO}_{4}$. By using DB-FFAP fused silica capillary column $(30 \mathrm{~m} \times 0.53 \mathrm{~mm})$ bonded with a $0.5-\mu \mathrm{m}$ layer of macrogol 20,000 2-nitroterephthalate materials used as stationary phase to provide very inert column that can accommodate the demanding analysis of acids dissolved in water. Elution of analytes was investigated using helium as carrier gas, with the constant column pressure of $75 \mathrm{kPa}$ and keeping the column oven temperature initially $80^{\circ} \mathrm{C}$ is maintained for $5 \mathrm{~min}$ and then increased to $190{ }^{\circ} \mathrm{C}$ at a rate of $10{ }^{\circ} \mathrm{C} / \mathrm{min}$, followed by holding at $190{ }^{\circ} \mathrm{C}$ for $15 \mathrm{~min}$. From this experimental trial, it was observed that all analytes were not

Table 6 Accuracy/recovery studies for sodium valproate

\begin{tabular}{lllll}
\hline Recovery level & Sample no. & 'ppm' added & 'ppm' recovered & \% Recovery \\
\hline LOQ \% & 1 & 0.5044 & 0.5057 & 100.25 \\
& 2 & 0.5044 & 0.5119 & 101.48 \\
& 3 & 0.5044 & 0.5049 & 100.09 \\
$100 \%$ & 1 & 1.0089 & 1.0091 & 99.02 \\
& 2 & 1.0089 & 1.0011 & 99.23 \\
& 3 & 1.0089 & 1.0020 & 97.94 \\
$150 \%$ & 1 & 1.5133 & 1.4821 & 98.31 \\
& 2 & 1.5133 & 1.4877 & 97.82 \\
& 3 & 1.5133 & 1.4803 & 94.69 \\
& 1 & 2.5222 & 2.3883 & 93.23 \\
& 2 & 2.5222 & 2.3515 & 92.32 \\
& 3 & 2.5222 & 2.3285 & 97.89 \\
\end{tabular}


Table 7 Solution stability for Standard

\begin{tabular}{ll}
\hline Solution stability: standard & \\
\hline Intervals & $\begin{array}{l}\text { Area \% difference } \\
\text { of Sodium } \\
\text { Valproate }\end{array}$ \\
\hline Initial & - \\
17 Hours & 0.4 \\
34 Hours & 0.5 \\
\hline
\end{tabular}

clearly separated. Satisfactory separation and better peak shapes were achieved within a reasonable time by flushing helium as the carrier gas with a constant pressure of $90 \mathrm{kPa}$ and initial column oven temperature of $190{ }^{\circ} \mathrm{C}$ is maintained for $28 \mathrm{~min}$ and then increased to $220^{\circ} \mathrm{C}$ at a rate of $10{ }^{\circ} \mathrm{C} / \mathrm{min}$, followed by holding at $220{ }^{\circ} \mathrm{C}$ for $1.7 \mathrm{~min}$.

The validation protocols such as accuracy, precision, linearity, specificity, sensitivity and robustness were observed to be within the acceptance limit. The correlation coefficient was within the acceptance criteria in the range of 0.999 . The evaluated concentrations for Sodium Valproate were in the ranges of 5.05-25.27 ppm. The average recovery values were in the range of 92.32 $101.48 \%$. Solution Stability experiments were performed to evaluate the degradation behavior of SVS. The validation parameters such as \% RSD of six replicate standard injections found to be $1.3 \%$ was observed to be within the limit. The tailing factor for the Sodium Valproate peak from the first standard injection was observed as 1.05 and was within the acceptance limit. The Theoretical plate for the Sodium Valproate peak from the first standard injection was found to be 64,907 and was observed to be within the limit. Finally, a new novel optimized method was developed and validated, with better peak shape and satisfactory separation was achieved on chromatographic conditions.

\section{Conclusions}

In this study, a novel, simple, highly sensitive and optimized cost-effective method was developed and validated consisting of six related substances in sodium valproate oral solution with GC with FID. Although numerous methods have been developed for determination of SV such as GC-MS, HPLC, LC-MS, etc., in this study six related substances were detected by using Gas Chromatography with Flame Ionization Detector. Compared with current methods, the most advantageous aspect of our method is its simple, rapid and highly sensitivity. So the method can be an efficient alternative method for the determination of related impurities. Furthermore, the proposed method is simple and user friendly and its
Table 8 Solution stability for Sample

\begin{tabular}{llll}
\hline \multicolumn{2}{l}{ Solution stability: sample } & & \\
\hline Intervals & $\begin{array}{l}\text { Area \% difference of } \\
\text { sodium valproate }\end{array}$ & $\begin{array}{l}\text { Any secondary } \\
\text { impurities }\end{array}$ & $\begin{array}{l}\text { Total } \\
\text { impurities }\end{array}$ \\
\hline Initial & - & $\mathrm{ND}$ & $\mathrm{ND}$ \\
17 Hours & -2.8 & $\mathrm{ND}$ & $\mathrm{ND}$ \\
34 Hours & -2.6 & $\mathrm{ND}$ & $\mathrm{ND}$ \\
\hline
\end{tabular}

ND Not detected

potential application makes it attractive for the routine analysis for the determination of related substances in sodium Valproate oral solution.

\section{Abbreviations}

SVS: Sodium Valproate Oral Solution; VPA: Valproic Acid; GC: Gas Chromatography; FID: Flame Ionization Detector; GC-MS: Gas Chromatography Mass Spectroscopy; LC-MS: Liquid Chromatography Mass Spectrometry; HPLC: High-Performance Liquid Chromatography; UPLC: Performance Liquid Chromatography; LOQ: Limit of quantification; GABA: Gamma-amino butyric acid; RS: Related Substance; ICH: International Council for Harmonization; HCl: Hydrochloric acid; \% RSD: Relative Standard Deviation.

\section{Acknowledgements}

Authors express their sincere gratitude to Seven Hills College of Pharmacy, Tirupati, for continuous motivation, support, and guidance for research activity and for providing all required facilities to accomplish the entitled work.

\section{Authors' contributions}

All the authors have equally contributed to the article. All authors read and approved the final manuscript.

Funding

Not applicable.

Availability of data and materials

Data and material are available upon request.

\section{Declarations}

Ethical approval and consent to participate Not applicable.

Consent for publication

Not applicable.

\section{Competing interests}

The authors declare that they have no competing interests.

\section{Author details}

${ }^{1}$ Department of Pharmacognosy, Seven Hills College of Pharmacy, Venkatramapuram, Tirupati, Chittoor 517561, Andhra Pradesh, India. ${ }^{2}$ Department of Pharmaceutical Analysis, Seven Hills College of Pharmacy, Venkatramapuram, Tirupati, Chittoor, Andhra Pradesh, India.

Received: 27 July 2021 Accepted: 22 September 2021

Published online: 09 October 2021

References

1. Lunde JL, Nelson RE, Storandt HF (2007) Acute seizures in a patient receiving divalproex sodium after starting ertapenem therapy. 
Pharmacotherapy 27(8):1202-1205. https://doi.org/10.1592/phco.27.8. 1202

2. Caruso JM, Brown WD, Exil G, Gascon GG (2000) The efficacy of divalproex sodium in the prophylactic treatment of children with migraine. Headache 40(8):672-676. https://doi.org/10.1046/j.1526-4610.2000.04000 8672.x

3. Ruedrich S, Swales TP, Fossaceca C, Toliver J, Rutkowski A (1999) Effect of divalproex sodium on aggression and self-injurious behaviour in adults with intellectual disability: a retrospective review. J Intellect Disabil Res 43(Pt 2):105-111. https://doi.org/10.1046/j.1365-2788.1999.00193.x

4. Albanese MJ, Clodfelter RC Jr, Khantzian EJ (2000) Divalproex sodium in substance abusers with mood disorder. J Clin Psychiatry 61 (12):916-921. https://doi.org/10.4088/jcp.v61n1205

5. Kemp DE, Gao K, Ganocy SJ, Elhaj O, Bilali SR, Conroy C, Findling RL, Calabrese JR (2009) A 6-month, double-blind, maintenance trial of lithium monotherapy versus the combination of lithium and divalproex for rapid-cycling bipolar disorder and co-occurring substance abuse or dependence. J Clin Psychiatry 70(1):113-121. https://doi.org/10.4088/jcp. $07 \mathrm{~m} 04022$

6. Reoux JP, Saxon AJ, Malte CA, Baer JS, Sloan KL (2001) Divalproex sodium in alcohol withdrawal: a randomized double-blind placebo-controlled clinical trial. Alcohol Clin Exp Res 25(9):1324-1329

7. Alsarra IA et al (2005) Valproic Acid and sodium valproate: comprehensive profile. Profiles Drug Subst Excip Relat Methodol 32:209-240. https://doi. org/10.1016/S0099-5428(05)32008-9

8. ICH Harmonized Tripartite guideline, Impurities in new drug substances Q3A (R2) Step 4 (2006)

9. Hage DS (2018) Chromatography. In: Principles and applications of clinical mass spectrometry: small molecules, peptides, and pathogens. Elsevier, pp 1-32. https://doi.org/10.1016/B978-0-12-816063-3.00001-3

10. Budiman H, Zuas O (2015) Comparison between GC-TCD and GC-FID for the determination of propane in gas mixture. Procedia Chem 16:465-472

11. Wood $\mathrm{MH}$ et al (1977) The estimation of plasma valproate by gas-liquid chromatography. Clin Chim Acta Int J Clin Chem 77(3):343-347. https:// doi.org/10.1016/0009-8981(77)90239-x

12. International Conference on Harmonization of technical requirements for registration of pharmaceutical for human use, ICH harmonized tripartite guideline, Validation of analytical procedures: Text and methodology, Q2 (R1), Step 4 (2005)
13. Raghavender Reddy S, Hussain Reddy K, Madhava Reddy P, Amarnatha Reddy G, Narendra Kumar M, Sharma HK (2017) Reliable GC method for related substances in divalproex sodium drug. J Chromatogr Sci 55(9):891-898. https://doi.org/10.1093/chromsci/bmx057

14. Lu H, Su C, Yin L, Gu L, Gu J, Chen X (2016) Liquid chromatographytandem mass spectrometry method for simultaneous determination of valproic acid and its ene-metabolites in epilepsy patient plasma. J Pharm Anal 6(2):112-116. https://doi.org/10.1016/j.jpha.2015.11.006

15. Ahmad Khaniha R, Rastkari N, Kobarfard F, Ahmad Khaniha O, Kebriaeizadeh A, Pakdaman H (2007) An improved GC method for rapid analysis of valproic acid in human plasma without derivatization. Iran J Pharm Sci 3(1):37-42

16. Reddy SR, Reddy KH, Kumar MN, Reddy PM, Reddy J, Sharma HK (2019) A validated GC-MS method for the determination of genotoxic impurities in divalproex sodium drug substance. J Chromatogr Sci 57(2):101-107. https://doi.org/10.1093/chromsci/bmy089

17. Stephenson JB, Flater ML, Bain LT (2016) Analysis of valproic acid, salicylic acid and ibuprofen in whole blood by GC-MS. J Anal Toxicol 40(8):649652. https://doi.org/10.1093/jat/bkw079

18. Abualhasan M, Odeh NW, Younis GN, Zeidan OF (2020) Analytical method development for sodium valproate through chemical derivatization. Int J Anal Chem. https://doi.org/10.1155/2020/5672183

19. Thakkar R, Saravaia H, Ambasana M, Patel M, Shah A (2012) An isocratic method for quantification of valproic acid and its related impurities using ion pair reagent by ultraperformance liquid chromatography. Int Sch Res Not. https://doi.org/10.5402/2012/836132

20. Lipska K, Gumieniczek A, Pietraś R, Filip AA (2021) HPLC-UV and GC-MS methods for determination of chlorambucil and valproic acid in plasma for further exploring a new combined therapy of chronic lymphocytic leukemia. Molecules 26(10):2903. https://doi.org/10.3390/molecules2 6102903

21. Mizuno S et al (2018) High-throughput determination of valproate in human samples by modified QuEChERS extraction and GC-MS/MS. Legal Med 4:66-73. https://doi.org/10.1016/j.legalmed.2018.01.002

\section{Publisher's Note}

Springer Nature remains neutral with regard to jurisdictional claims in published maps and institutional affiliations.

\section{Submit your manuscript to a SpringerOpen ${ }^{\circ}$ journal and benefit from:}

- Convenient online submission

- Rigorous peer review

- Open access: articles freely available online

- High visibility within the field

- Retaining the copyright to your article

Submit your next manuscript at $\boldsymbol{\nabla}$ springeropen.com 